\title{
Effects of taper and space settings of telescopic Ce-TZP/A crowns on retentive force and settling
}

\author{
Shusuke NAKAGAWA, Katsunori TORII and Masahiro TANAKA \\ Department of Fixed Prosthodontics and Occlusion, Osaka Dental University, 1-5-17 Otemae, Chuo-ku, Osaka 540-0008, Japan \\ Corresponding author, Shusuke NAKAGAWA; E-mail: nakagawa@cc.osaka-dent.ac.jp
}

\begin{abstract}
The aim of this study was to investigate the effect of the taper and space setting of using Ce-TZP/A on retentive force and secondary crown settling. The taper were $2^{\circ}, 4^{\circ}$, and $6^{\circ}$, and the space settings were 0 and $10 \mu \mathrm{m}$. The applied loads were 50 and $100 \mathrm{~N}$. The taper had a significant effect on retentive force and settling at both loads $(p<0.05)$. The space settings did not have a significant effect on retentive force or settling at either load $(p<0.05)$. The taper of the telescopic crowns and the load affected the retentive force and the settling.
\end{abstract}

Keywords: Telescopic crowns, CAD/CAM, Ce-TZP/A, Taper, Retentive force

\section{INTRODUCTION}

The telescopic crowns have been used as attachments for decades, and are a reliable type of treatment with favorable survival ${ }^{1-4}$. While telescopic crowns using dental alloys have recently become more popular, these cannot be used in patients with metal allergies ${ }^{5-7)}$. Moreover, to ensure an appropriate retentive force, the crowns must be fitted by experienced dental technicians, who check that the axis surfaces of the primary and secondary crowns are tightly fitted, and there are slight spaces between the occlusal surfaces of the primary and secondary crowns ${ }^{8}$. In the present study, the stability and technical accuracy of telescopic crowns made of dental zirconia were estimated, using a computer-aided design/computer-aided manufacturing (CAD/CAM), which have recently been attracting attention.

Generally, yttrium-stabilized tetragonal zirconia polycrystal (Y-TZP) is used for dental zirconia, but Y-TZP has a fatal flaw in that its strength deteriorates at low temperatures ${ }^{9,10)}$. A zirconia/alumina nanocomposite stabilized with cerium oxide (Ce-TZP/A) was developed to overcome this flaw. Ce-TZP/A has desirable mechanical qualities, and compared to Y-TZP, it has superior thermal stability and toughness, therefore it is in the spotlight as a new material candidate ${ }^{11,12}$. This material has an interpenetrated intragranular nanostructure, in which either nanometer-sized Ce-TZP or $\mathrm{Al}_{2} \mathrm{O}_{3}$ particles locate within submicron-sized $\mathrm{Al}_{2} \mathrm{O}_{3}$ or Ce-TZP grains, respectively. This material design makes it possible to strengthen the $10 \mathrm{~mol} \%$ ceria-stabilized TZP matrix with $30 \mathrm{vol} \% \mathrm{Al}_{2} \mathrm{O}_{3}$. In comparison to Y-TZP, the Ce-TZP/A has a high biaxial flexure strength and toughness, along with satisfied durability in terms of low-temperature aging degradation in various aqueous conditions encountered in dentistry ${ }^{9,13)}$. Also, the disk of presintered Ce-TZP/A in this experiment was $98.3 \mathrm{~mm}$ in diameter, $14.0 \mathrm{~mm}$ in thickness, 1.204 in expansion coefficient. The shrinkage of the disk was $16.96 \%$ in outer diameter direction, $17.05 \%$ in thickness direction. Furthermore, the CAD/CAM is suitable for producing telescopic crown because the design of the dental prosthetics can be freely modified before production ${ }^{14-17}$.

A great deal of research has already been conducted on the retentive force of telescopic crowns dentures made using dental alloys ${ }^{18-20}$. In particular, it has been reported that the retentive force is reliant on the taper of the primary crown and the load, and if the taper is small or the load is large, the retentive force increase ${ }^{19,20)}$. This phenomenon is thought to be due to the wedge effect caused by the settling of the secondary crown, which affects the retentive force. Furthermore, the setting of the space between the primary crown and the inner surface of the secondary crown is also thought to affect the retentive force and the settling of the secondary crown.

The aim of this research was to investigate the effect of three different tapers and two different spaces on the retentive force and the settling of the secondary crown. The tested hypotheses were that the effect of taper and space settings of telescopic Ce-TZP/A crowns were crucial to retentive force and settling.

\section{MATERIALS AND METHODS}

The composition of the materials used in this study are listed in Table 1. Ce-TZP/A was used for the primary crown and secondary crown. The primary crown morphology was defined according to the mean anatomical size of premolars and molars ${ }^{21)}$, and values used in previous reports ${ }^{16,18,19}$. The primary crown was integrated with the abutment tooth. The design of primary crown was used for the CATIA software (Dassault Systemes, Vélizy-Villacoublay, France). The tooth cervix was an oblong shape with a major axis measuring $8 \mathrm{~mm}$, and a minor axis measuring $6 \mathrm{~mm}$. The vertical dimension was $6.5 \mathrm{~mm}$ with a flat top, and the corner between the axis surface and occlusal surface 
Table 1 Materials used in this study

\begin{tabular}{cllll}
\hline Code & \multicolumn{1}{c}{ Product Name } & \multicolumn{1}{c}{ Manufacturer } & \multicolumn{1}{c}{ Composition } & Lot. No. \\
\hline \multirow{2}{*}{ Ce-TZP/A } & C-Pro Nano-zirconia & $\begin{array}{l}\text { Panasonic Healthcare, } \\
\text { Japan }\end{array}$ & $\begin{array}{l}10 \mathrm{~mol}_{\%} \mathrm{CeO}_{2}-\mathrm{ZrO}_{2} \\
30 \mathrm{vol}_{\mathrm{Al} \mathrm{Al}_{3}}\end{array}$ & $15220 \mathrm{E} 007$ \\
\hline
\end{tabular}

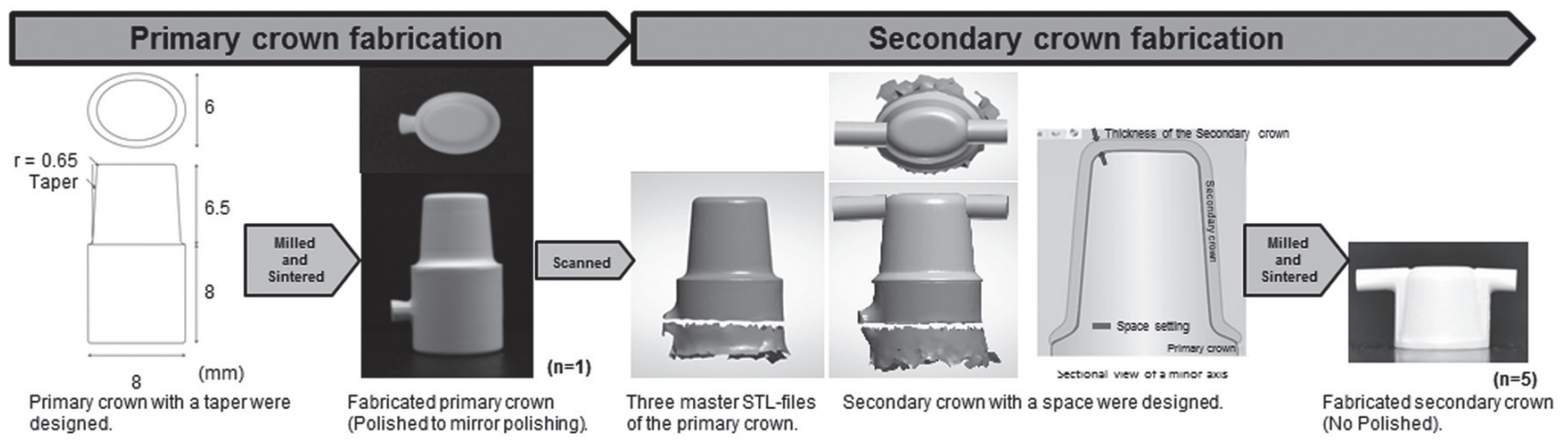

Fig. 1 Fabricated primary crown and secondary crown.

was rounded with a curvature radius of $0.65 \mathrm{~mm}$. The shape of the tooth cervix margin had a deep chamfer form with a curvature radius of $0.8 \mathrm{~mm}$. The taper was set as $2^{\circ}, 4^{\circ}$, and $6^{\circ}$. Afterwards, each primary crown was milled (CAM250i, Panasonic Healthcare, Tokyo, Japan). A knob was allocated to one location as an indicator for the direction of secondary crown repositioning. One primary crown was produced for each of the taper. Sintering was then performed as per the manufacturer's instructions using a sintering furnace (inFire HTC, Sirona Dental Systems, St Leonards, NSW, Australia). The primary crown was sintered for about five hours to $1,450^{\circ}$ and was held at $1,450^{\circ}$ for two hours and was cooled naturally. The primary crowns got their precise taper of $2^{\circ}, 4^{\circ}$ and $6^{\circ}$ by grounding and milling (Horico diamond point $\left(2^{\circ}\right)$, $\left(4^{\circ}\right),\left(6^{\circ}\right)$, Ringleb, Berlin, Germany, LOT 19511, LOT 08623, LOT 22974), using an electric, high-speed handpiece, mounted in a surveyor device (Bego Paraskop, BEGO Bremer Goldschlägerei Wilh. Herbst, Brernen, Germany). Afterwards, all primary crown were polished with silicone polisher (CERAMASTER Coarse, Shofu, Kyoto, Japan, LOT 0216164), brushes, and a polishing paste (Zircon-Brite, Dental Ventures of America, Corona, CA, USA, LOT 7670), using a handpiece. Accuracy of dimension in each types of the primary crown was researched. CT images of the primary crown were taken using a microfocus X-ray CT. The captured images were converted to $3 \mathrm{D}$ construction images using the $3 \mathrm{D}$ volume rendering software VG Studio Max1.2 (Volume Graphics, Heidelberg, Germany) ${ }^{22)}$. The taper of the primary crown was measured with VG Studio Max on the CT images in regard to major axis side and minor axis side. The taper of the primary crown fabricated at $2^{\circ}$ was $2.02^{\circ}$ with major axis side and $1.98^{\circ}$ with minor axis side. The taper of the primary crown fabricated at $4^{\circ}$ was $4.04^{\circ}$ with major axis side and $4.04^{\circ}$ with minor axis side. The taper of the primary crown fabricated at $6^{\circ}$ was $6.04^{\circ}$ with major axis side and $6.02^{\circ}$ with minor axis side. Accuracy of dimension in each types of the primary crown was verified.

First, the measurements of the fabricated primary crown were acquired using the D-810 scanner (3shape, Copenhagen, Denmark). Then, the design of the secondary crown was created using CAD software (Dental System 2015, 3shape), based on the primary crown data. The minimal thickness of the secondary crown was set at $0.4 \mathrm{~mm}$. The space between the primary crown and secondary crown was set as 0 and $10 \mu \mathrm{m}$. Two knobs with different lengths were also allocated to the outside surface of the secondary crown to measure retentive force. The difference in the lengths of the two knobs was used as an index for the repositioning direction of the secondary crown. Five secondary crowns were produced for each of the spacing conditions using the CAD/CAM. Sintering of the secondary crown was performed using a sintering program with the same conditions as those set for the primary crown. The secondary crowns were not polished (Fig. 1).

After the secondary crown was repositioned on the primary crown, a 50 or $100 \mathrm{~N}$ load was placed on the secondary crown for $15 \mathrm{~s}$ using a tensile testing machine (EZTest, Shimadzu, Kyoto, Japan). The position of the secondary crown was standardized with the direction of the longer knob of the secondary crown being on the same side of the primary crown knob. Then, a polyethylene line was placed on the knob on the secondary crown, and vertical traction was exerted on the outer crown with a crosshead speed of $40 \mathrm{~mm} / \mathrm{min}$ (Fig. 2). The maximum measured value was recorded as the retentive force. The measurements were taken five times, and the mean values were calculated. 


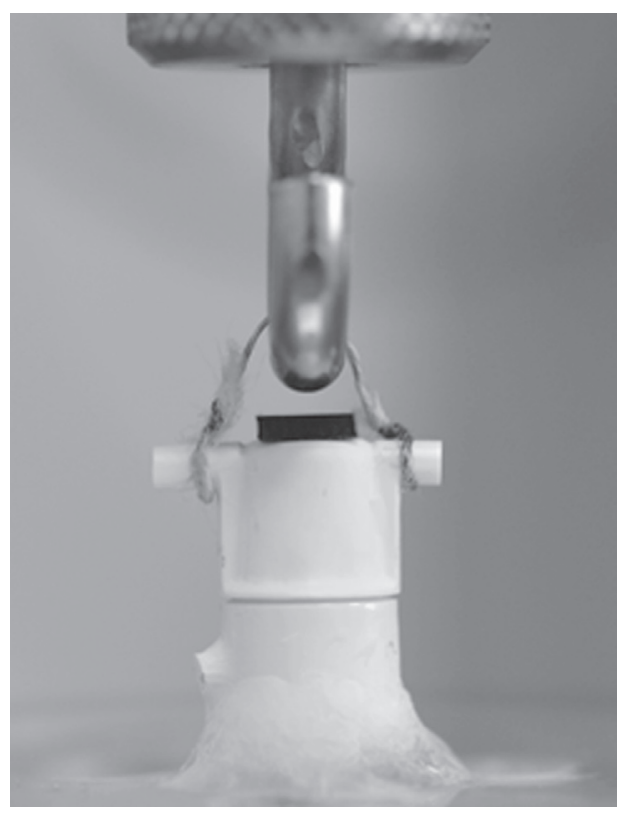

Fig. 2 Measurement of retentive force.

\section{(A)}

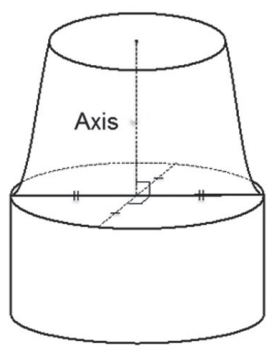

(B)

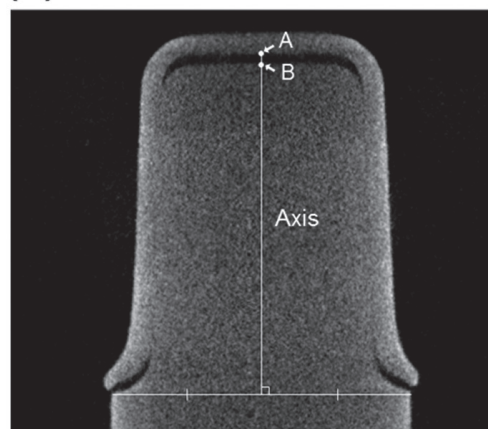

Fig. 3 Measurement of the interspace (A) The primary crown axis. (B) Sectional view of primary and secondary crowns.

A: Intersection of primary crown axis and secondary crown inside. B: Intersection of primary crown axis and primary crown outside.

First, the secondary crown was repositioned on the primary crown, and CT images of the primary and secondary crown were taken using a microfocus X-ray CT (SMX-130CT, Shimadzu), with no load, a 50 or $100 \mathrm{~N}$ load using a pressure testing machine for 15 s. A microfocus X-ray CT was used for nondestructive testing. The imaging conditions were set as $130 \mathrm{kV}$ for the X-ray tube voltage and $120 \mu \mathrm{A}$ for the tube current. The captured images were converted to $3 \mathrm{D}$ construction images using the $3 \mathrm{D}$ volume rendering software $\mathrm{VG}$ Studio Max1.2. The interspace between primary and secondary crowns was measured with VG Studio Max
Table 2 Factors and levels

\begin{tabular}{cccc}
\hline Factors & \multicolumn{3}{c}{ Levels } \\
Taper & $2^{\circ}$ & $4^{\circ}$ & $6^{\circ}$ \\
Space & $0 \mu \mathrm{m}$ & & $10 \mu \mathrm{m}$ \\
\hline
\end{tabular}

on the CT images (Fig. 3). The length of settling was the interspace with a 50 or $100 \mathrm{~N}$ load and the interspace with no load.

A two-way factorial analysis of variance (ANOVA) of the retentive force and settling at 50 and $100 \mathrm{~N}$ loads was performed with the factors and levels shown in Table 2. The level of significance was set as 5\%. When the taper was found to be a significant factor multiple comparisons were conducted using the Bonferroni correction method. IBM SPSS Statistics ver. 19 (IBM Japan, Tokyo, Japan) was used for the analyses. Power analysis was performed for support the sample size. Power (1- $\beta$ ) was calculated from the sample size, the level of statistical significance, and the effect size. The $\mathrm{p} \eta^{2}$ was calculated to the effect size ${ }^{23)}$. G Power software (Ver. 3.1, Heinrich Heine University, Düsseldorf, Germany) was used for the power analysis ${ }^{24)}$.

\section{RESULTS}

After loading, no fracture or crack was found in all samples and four examined Power (1- $\beta$ ) were the same value.

The taper was found to have a significant effect on retentive force at a $50 \mathrm{~N}$ load $(p<0.001)$. The multiple comparison results showed significance at all levels. The measured retentive forces are shown in Fig. 4 . The mean retentive force was $23 \mathrm{~N}$ with a $2^{\circ}, 8 \mathrm{~N}$ with a $4^{\circ}$, and no retentive force with a $6^{\circ}$ taper. The space setting was not significant $(p=0.129)$. The interaction was not significant $(p=0.524)$. Power (1- $\beta)$ as calculated from the sample size, level of statistical significance, and size effect was 1.00 .

The taper was also found to be a significant factor at a $100 \mathrm{~N}$ load $(p<0.001)$. The multiple comparison results showed significance at all levels. The measured retentive forces are shown in Fig. 5. The mean retentive force was $47 \mathrm{~N}$ with a $2^{\circ}, 15 \mathrm{~N}$ with a $4^{\circ}$, and no retentive force with a $6^{\circ}$ taper. The space setting was not significant $(p=0.215)$. The interaction was not significant $(p=0.499)$. The power (1- $\beta$ ) was 1.00 .

The taper was found to have a significant effect on the settling at a $50 \mathrm{~N}$ load $(p<0.001)$. The multiple comparison results showed significance at all levels. The measured settling amounts are shown in Fig. 6. The mean settling was $234 \mu \mathrm{m}$ with a $2^{\circ}, 135 \mu \mathrm{m}$ with a $4^{\circ}$, and $26 \mu \mathrm{m}$ with a $6^{\circ}$ taper. The space setting was not significant $(p=0.086)$. The interaction was not significant $(p=0.135)$. The power $(1-\beta)$ was 1.00 .

The taper was also found to have a significant effect on the settling at a $100 \mathrm{~N}$ load $(p<0.001)$. The 


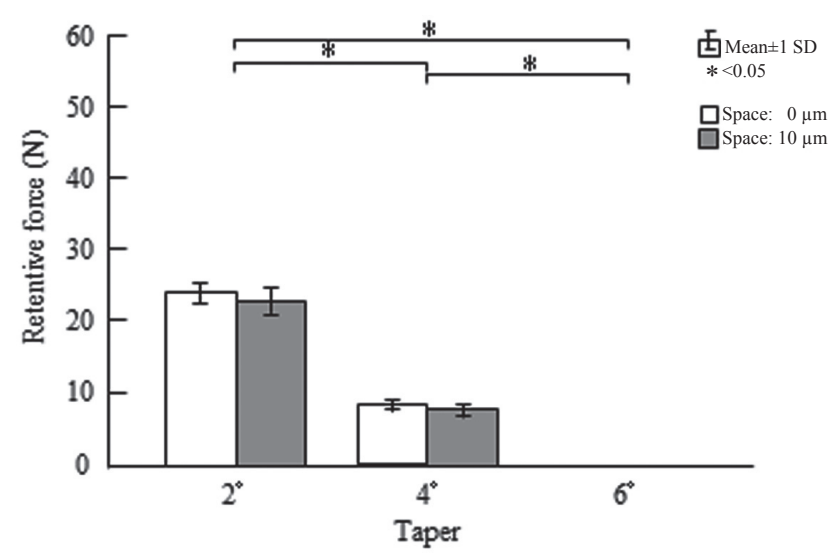

Fig. 4 Retentive force according to taper and space setting at $50 \mathrm{~N}$ load.

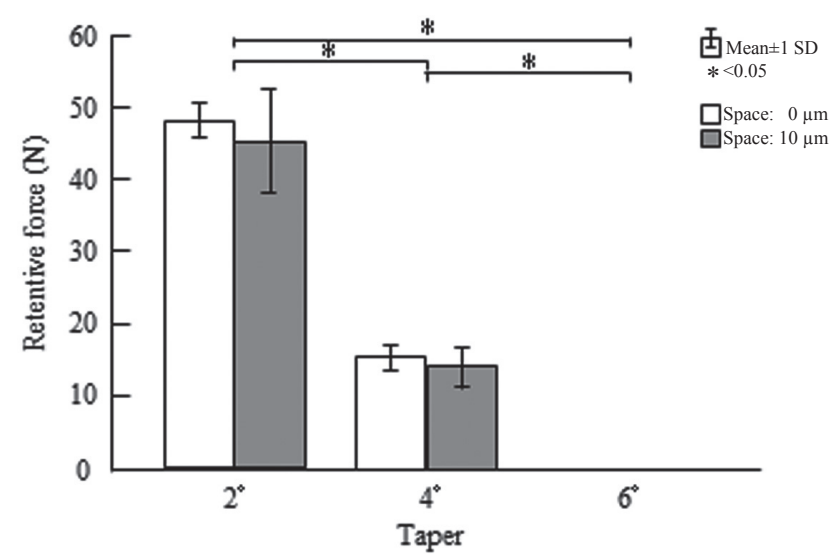

Fig. 5 Retentive force according to taper and space setting at $100 \mathrm{~N}$ load.

multiple comparison results showed significance at all levels. The measured settling amounts are shown in Fig. 7. The mean settling was $286 \mu \mathrm{m}$ with a $2^{\circ}, 162 \mu \mathrm{m}$ with a $4^{\circ}$ and $60 \mu \mathrm{m}$ with a $6^{\circ}$ taper. The space setting was not significant $(p=0.227)$. The interaction was not significant $(p=0.267)$. The power $(1-\beta)$ was 1.00 .

\section{DISCUSSION}

In this study, the taper, primary and secondary crown space, and the load were controlled. The retentive force with the conventional telescopic crown method is generated when the secondary crown is fitted onto the primary crown by applying a force to the secondary crown, and even when that force is removed the secondary crown retains its position, exhibiting a wedge effect ${ }^{16,19)}$. In other words, surface drag is generated on the contact surfaces of the primary and secondary crown, and this becomes the retentive force. Theoretically, the retentive force can be adjusted by

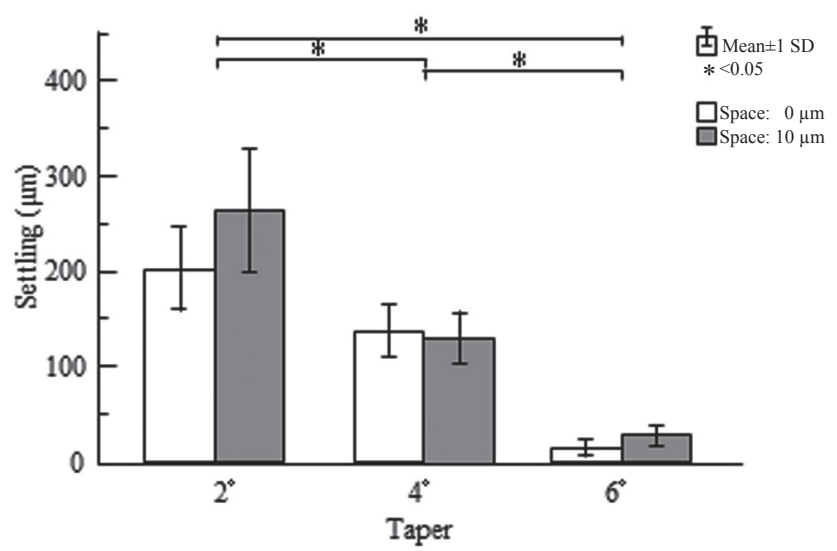

Fig. 6 Settling according to taper and space setting at 50 $\mathrm{N}$ load.

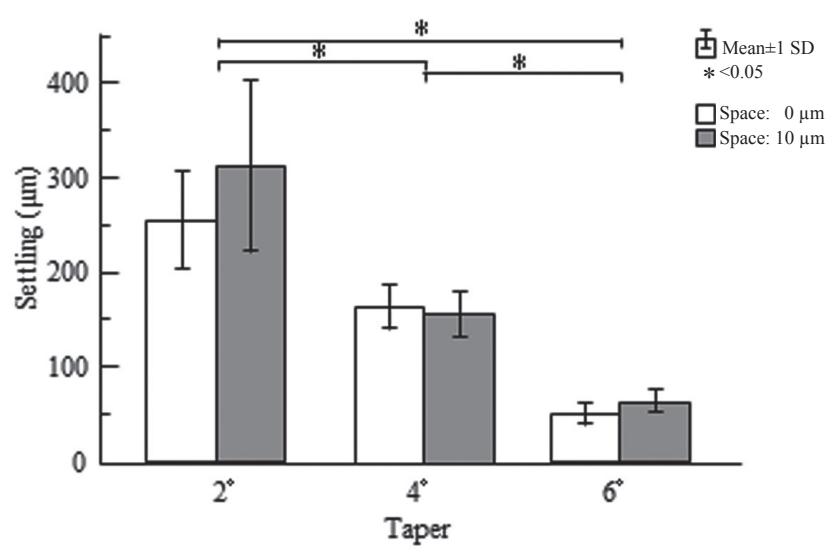

Fig. 7 Settling according to taper and space setting at 100 $\mathrm{N}$ load.

controlling the taper, load, and coefficient of static friction. For example, if the taper is small and the load is large, the coefficient of static friction increases, and then the retentive force increases as a result. Furthermore, reports show that if there is no gap between the occlusal surfaces of the primary and secondary crown during fitting, the retentive force due to the wedge effect will not be expressed. Based on the above information, the taper, the setting of the space, and the load were investigated in the current study.

The taper was initially set at $6^{\circ}$, which is the setting frequently used in clinical practice for conventional telescopic crowns, which is $6^{\circ}$ taper $^{19)}$. In the preliminary experiment, the Ce-TZP/A coefficient of static friction was 0.1 . This is 0.3 to $0.4^{25)}$ smaller than a metal alloy, therefore additionally, taper of $2^{\circ}$ and $4^{\circ}$ were investigated.

The space between the primary crown and secondary crown was set at 0 and $10 \mu \mathrm{m}$. Perel ${ }^{20)}$ compared the retentive force after embedding the secondary crown 
wax pattern in investment compounds with differing amounts of expansion and fabricating the secondary crown pattern. Therefore, in this study, the effects of the space settings between the primary crown and secondary crown on the retentive force were investigated.

The load was set as 50 and $100 \mathrm{~N}$. Niwatcharoenchaikul et $a .^{26)}$ measured the occlusal forces generated in complete dentures, and reported that peanuts generated forces of 161 to $181 \mathrm{~N}$. Anderson $^{27}$ measured the occlusal forces in natural teeth and reported it as $8 \mathrm{~kg}$ or less. The occlusal forces exerted on the outer crowns in this study were chosen based on the above information.

Güngör et al. ${ }^{19)}$ reported that the telescopic crowns retentive force increases as the taper becomes smaller. In this study, similar results were found with all load conditions irrespective of the primary and secondary crown space setting. Conversely, the settling increases with smaller taper. If wedges with different tapers are driven in with the same amount of force, sharp wedges are driven in more easily and go in the deepest, making removal difficult. In other words, even with telescopic crowns, if the taper is small, a large surface drag is generated and a high level of retentive force is generated due to the wedge effect ${ }^{4,16,19,20)}$.

The appropriate retentive force in clinical practice is 5 to $9 \mathrm{~N}$ for one abutment device, and the taper that expresses this retentive force in metal alloys is $6^{\circ}$ taper ${ }^{19)}$. In this study, the condition under which the appropriate retentive force was achieved a $4^{\circ}$ taper with a $50 \mathrm{~N}$ load. The differences in the tapers can be explained by the material's coefficient of static friction. Ohida et al. ${ }^{25)}$ used Körber's equation for the telescopic crown retentive force, and compared the retentive forces of $\mathrm{Co}-\mathrm{Cr}$ alloys, $\mathrm{Ti}$ alloys, $\mathrm{Pd}-\mathrm{Ag}$ alloys, and $\mathrm{Au}$ alloys. According to that report, the coefficient of static friction was approximately $0.2,0.3,0.35$, and 0.4 , respectively. In other words, the tapers of Co-Cr alloys, $\mathrm{Ti}$ alloys, and $\mathrm{Pd}-\mathrm{Ag}$ alloys must be set at a lower value than that of $\mathrm{Au}$ alloys. The Ce-TZP/A coefficient of static friction was found in the preliminary experiment to be 0.1 , so the tapers was set at $4^{\circ}$, which is smaller than the metal alloy tapers of $6^{\circ}$. Furthermore, Fingerhut et $a l{ }^{28)}$ reported that there was a correlation between the retentive force/the load and the tapers, using Y-TZP crowns with a coefficient of static friction of 0.08 . They found that the appropriate retentive force was expressed when the taper was approximately $3^{\circ}$ with a $50 \mathrm{~N}$ load. They also measured the retentive forces with tapers of $2^{\circ}$ and $6^{\circ}$ and found them to be approximately 20 and $0 \mathrm{~N}$, respectively. This was close to the results of this study.

The results of this study demonstrate that the primary and secondary crown space settings did not affect the retentive force and the settling. An increase in size of friction area increases the retentive force ${ }^{25,29)}$. In other words, the contact area of the crown axis surface is closely related to the retentive force. The effect of the taper is extremely resilient to incompatibilities between the primary and secondary crown ${ }^{20)}$. They found that even if the secondary crown is deformed during the casting process, as long as the cone angle is kept constant, the primary and secondary crown are secured by the crown axis surface, and their position is maintained effectively. In this study, the primary and secondary crown spacing did not affect the crown axis surface contact area. As a result, it is also thought to not affect the retentive force and the settling.

When the retentive force with 50 and $100 \mathrm{~N}$ loads was compared, approximately two times the retentive force was achieved with the $2^{\circ}$ and $4^{\circ}$ tapers. Similar results were obtained with conventional studies using dental alloys ${ }^{16,19,20)}$. Conversely, the results of the settling in this experiment indicated that the larger the load amount, the greater the settling. That is to say, the secondary crown underwent elastic deformation due to the load. Therefore, if the load increases, the amount of elastic deformation of the secondary crown also increases, and that contractile force is probably expressed as a high retentive force ${ }^{19)}$.

According to this laboratory study, telescopic CeTZP/A crowns with a $2^{\circ}$ taper showed the highest retentive force values, whereas taper $6^{\circ}$ showed the lowest retentive force values. The increase of the load led to the increase of the retentive force. The space setting showed no effect on the retentive force.

Telescopic Ce-TZP/A crowns with a $2^{\circ}$ taper showed the highest settling amounts values, whereas taper $6^{\circ}$ showed the lowest settling amounts values. The increase of the load led to the increase of the settling. The space setting showed no effect on the settling. The taper of telescopic Ce-TZP/A crowns affected the retentive force and the settling of secondary crowns.

Based on this study, $4^{\circ}$ taper with a $50 \mathrm{~N}$ load is the most appropriate. At $2^{\circ}$ taper and $4^{\circ}$ taper, the settling of the secondary crown exhibited the wedge effect and brought about retentive force. The above results show that telescopic Ce-TZP/A crowns will be available in clinical applications. However, further research is needed to validate the telescopic crowns using CeTZP/A, including an assessment of the morphology of the primary crown and secondary crown, the effect of repeated application and removal of the secondary crown on retentive force, and quantification of the various errors during the manufacturing process.

\section{ACKNOWLEDGMENTS}

This study was funded by the No.15-03 grant from the FY2015 Osaka Dental University Grant-in-Aid for Encouraging Scientific Research. There are no relevant conflicts of interests to declare.

\section{REFERENCES}

1) Wöstmann B, Balkenhol M, Weber A, Weber A, Ferger P, Rehmann P. Long-term analysis of telescopic crown retained removable partial dentures: Survival and need for maintenance. J Dent 2007; 35: 939-945.

2) Koller B, Att W, Strub JR. Survival rates of teeth, implants, and double crown-retained removable dental prostheses: a 
systematic literature review. Int J Prosthodont 2011; 24: 109117.

3) Verma R, Joda T, Brägger U, Wittneben JG. A systematic review of the clinical performance of tooth-retained and implant-retained double crown prostheses with a follow-up of $\geq 3$ years. J Prosthodont 2013; 22: 2-12.

4) Beschnidt SM, Chitmongkoisuk S, Prull R. Telescopic crownretained removable partial dentures: review and case report. Compend Contin Educ Dent 2001; 22: 929-932.

5) Levi L, Barak S, Katz J. Allergic reactions associated with metal alloys in porcelain-fused-to-metal fixed prosthodontic devices -A systematic review. Quintessence Int 2012; 43: 871-877.

6) Javed F, Al-Hezaimi K, Almas K, Romanos GE. Is titanium sensitivity associated with allergic reactions in patients with dental implants? A systematic review. Clin Implant Dent Relat Res 2013; 15: 47-52.

7) Gökçen-Röhlig B, Saruhanoglu A, Cifter ED, Evlioglu G. Applicability of zirconia dental prostheses for metal allergy patients. Int J Prosthodont 2010; 23: 562-565.

8) Wagner B, Kern M. Clinical evaluation of removable partial dentures 10 years after insertion: success rates, hygienic problems, and technical failures. Clin Oral Investig 2000; 4: 74-80.

9) Ban S, Sato H, Suehiro Y, Nakanishi H, Nawa M. Biaxial flexure strength and low temperature degradation of Ce-TZP/ $\mathrm{Al} 2 \mathrm{O} 3$ nanocomposite and Y-TZP as dental restoratives. $\mathrm{J}$ Biomed Mater Res B Appl Biomater 2008; 87: 492-498.

10) Lughi V, Sergo V. Low temperature degradation - aging - of zirconia: A critical review of the relevant aspects in dentistry. Dent Mater 2010; 26: 807-820.

11) Miyazaki T, Nakamura T, Matsumura H, Ban S, Kobayashi T. Current status of zirconia restoration. J Prosthodont Res 2013; 57: 236-261.

12) Tanaka S, Takaba M, Ishiura Y, Kamimura E, Baba K. A 3-year follow-up of ceria-stabilized zirconia/ alumina nanocomposite (Ce-TZP/A) frameworks for fixed dental prostheses. J Prosthodont Res 2015; 59: 55-61.

13) Ban S, Nawa M, Sugata F, Tsuruki J, Kono H, Kawai T. HRTEM observation of bonding interface between Ce-TZP/ $\mathrm{Al}_{2} \mathrm{O}_{3}$ nanocomposite and porcelain. Dent Mater J 2014; 33 : 565-569.

14) Bergler M, Holst S, Blatz MB, Eitner S, Wichmann M. CAD/ CAM and telescopic technology: design options for implantsupported overdentures. Eur J Esthet Dent 2008; 3: 66-88.

15) Groesser J, Sachs C, Heiß P, Stadelmann M, Erdelt K, Beuer F. Retention forces of 14-unit zirconia telescopic prostheses with six double crowns made from zirconia-an in vitro study. Clin Oral Investig 2014; 18: 1173-1179.

16) Shimakura M, Nagata T, Takeuchi M, Nemoto T. Retentive force of pure titanium konus telescope crowns fabricated using CAD/CAM system. Dent Mater J 2008; 27: 211-215.

17) Schwindling FS, Stober T, Rustemeier R, Schmitter M, Rues S. Retention behavior of double-crown attachments with zirconia primary and secondary crowns. Dent Mater 2016; 32: 695-702.

18) Sakai Y, Takahashi H, Iwasaki N, Igarashi Y. Effects of surface roughness and tapered angle of cone crown telescopic system on retentive force. Dent Mater J 2011; 30: 635-641.

19) Güngör MA, Artunç C, Sonugelen M. Parameters affecting retentive force of conus crowns. J Oral Rehabil 2004; 31: 271277.

20) Perel ML. Telescope dentures. J Prosthet Dent 1973; 29: 151156.

21) Brace CL, Nagai M. Japanese tooth size: part and present. Am J Phys Anthropol 1982; 59: 399-411.

22) Kamegawa M, Nakamura M, Fukui Y, Tsutsumi S, Hojo M. Direct 3-D morphological measurements of silicone rubber impression using micro-focus X-ray CT. Dent Mater J 2010; 29: 68-74

23) Olejnik S, Algina J. Measures of effect size for comparative studies: applications, interpretations, and limitations. Contemp Educ Psychol 2000; 25: 241-286.

24) Faul F, Erdfelder E, Buchner A, Lang AG. Statistical power analyses using $\mathrm{G}^{*}$ Power 3.1: test for correlation and regression analyses. Behav Res Methods 2009; 41: 1149-1160.

25) Ohida $M$, Yoda $K$, Nomura $N$, Hanawa $T$, Igarashi $Y$. Evaluation of the static fiction coefficients of $\mathrm{Co}-\mathrm{Cr}$ and gold alloys for cone crown telescope denture retainer applications. Dent Mater J 2010; 29: 706-712.

26) Niwatcharoenchaikul W, Tumrasvin W, Arksornnukit M. Effect of complete denture occlusal schemes on masticatory performance and maximum occlusal force. J Prosthet Dent 2014; 112: 1337-1342.

27) Anderson DJ. A method of recording masticatory loads. J Dent Res 1953; 32: 785-789.

28) Fingerhut C, Schindler HJ, Schweizerhof K. Kordass B, Lenz J. Finite element analysis of the principles and loosening force of the conical telescopic crown: a computer-based study. Int J Comput Dent 2014; 17: 199-218.

29) Stock V, Wagner C, Merk S, Roos M, Schmidlin PR, Eichberger M, Stawarczyk B. Retention force of differently fabricated telescopic PEEK crowns with different tapers. Dent Mater J 2016; 35: 594-600. 